\title{
Monitoring landed seahorse catch in a changing policy environment
}

\author{
M. Yasué ${ }^{1, *}$, A. Nellas ${ }^{2}$, H. Panes ${ }^{2}$, A. C. J. Vincent ${ }^{3}$ \\ ${ }^{1}$ Quest University Canada, 3200 University Blvd., Squamish, BC V8B 0N8, Canada \\ ${ }^{2}$ Project Seahorse Foundation for Marine Conservation, Gaviola Compound, Maria Theresa Village II, \\ Barangay Guadalupe 6000, Philippines \\ ${ }^{3}$ Fisheries Centre, University of British Columbia, 2202 Main Mall, Vancouver, BC V6T 1Z4, Canada
}

\begin{abstract}
For many small-scale, tropical reef fisheries, landed catch may be the only data that can be monitored to assess the impacts of management. This is true for seahorses Hippocampus comes that are obtained as part of a multi-species fishery in the Philippines. Here, because seahorses are locally rare and depleted, it is difficult to attain large enough sample sizes to detect changes over time using underwater surveys. We assessed changes in seahorse sales at 2 sites, from 1996 and 2005 respectively to 2010. The study period covered local and national conservation initiatives that could affect seahorses and dependent fisheries: establishment of marine reserves (1998 onwards), a community-led minimum size limit (MSL: 2002 to 2004) and a national ban on seahorse fishing (from 2004). The MSL appeared to lead to increased sizes of seahorses in trade, as hoped, while the national ban led, perversely, to more fishers selling seahorses. Declines in overall take after 2004 or 2007 (depending on the site) is likely linked to declining seahorse populations rather than reduced effort, especially when one considers the increased number of fishers and the price per seahorse. It is notable that communities decided on the MSL, whereas the government imposed the ban on capturing seahorses. In this small-scale, multi-species fishery, monitoring a wide range of variables intensively over a relatively long time scale allowed us to identify key differences between small-scale and industrial fisheries management, and also to document the biological and social consequences of management action for a depleted, threatened species.
\end{abstract}

KEY WORDS: CITES - MPAs - Marine reserve - Exploitation - Fishing ban - Philippines · Size distribution $\cdot$ Minimum size limits

\section{INTRODUCTION}

The biophysical and socioeconomic changes that occur over multiple and extensive spatial and temporal scales in the oceans make effective monitoring especially costly and difficult (Ludwig et al. 1993, Norse \& Crowder 2005). Yet data-poor and overexploited marine species are priorities for evidencebased conservation, with multi-year studies needed to assess the biological or social effects of conservation projects (Sutherland et al. 2004). In addition to

${ }^{*}$ Corresponding author: maiyasue@gmail.com the inherent complexity of marine systems, in contrast to terrestrial species, remarkably little is known about the conservation of threatened fish species (Hudson \& Mace 1996, Polidoro et al. 2008), with research emphasis in the past focusing only on the exploitation of fish.

For exploited marine species, fisheries-dependent landed catch data is generally the most logistically feasible approach to monitoring changes in fish populations over time (Murphy \& Jenkins 2010, Pauly et al. 2013). Data such as fish number and size reflect

() The authors 2015. Open Access under Creative Commons by Attribution Licence. Use, distribution and reproduction are unrestricted. Authors and original publication must be credited. 
fishing pressure and are comparatively cheaply obtained. Moreover, techniques can be quickly and effectively taught to non-professionals. Fisheriesdependent surveys do have notable limitations, such as the inability to monitor fish that are not captured in size-selective fishing gear (Murphy \& Jenkins 2010) or a tendency to confound increases in effort with changes in abundance (Gillis et al. 1993). Still, such sampling of catch allow monitoring of a much greater number of individuals and over longer time scales than could be obtained with fisheries independent methods such as underwater visual surveys (Roberts et al. 2001). Gaining sufficient sample sizes for the necessary comparisons of change before and after conservation interventions is a particular concern for species that are severely depleted and locally rare (Yasué et al. 2012).

Catch landings data may be an important source of information for tropical multi-species reef fisheries, which commonly are particularly data-poor and difficult to monitor and manage using conventional single-species fisheries management approaches (Johannes 1998, Castilla \& Defeo 2005, Vincent et al. 2007). These fisheries provide an important source of food or income for often impoverished fishers (Sadovy 2005) but they generally lack formal stock assessments, national monitoring programs or management plans (McClanahan et al. 2007, Vincent et al. 2007). The sheer number of fishers, however, means that these fisheries have the capacity to harm fish populations, including rare taxa (Sadovy \& Cheung 2003, Dulvy \& Polunin 2004).

We focus on the tiger-tail seahorse Hippocampus comes Cantor, 1850, a Southeast Asian species that has been assessed as Vulnerable on the IUCN Red List and placed on CITES Appendix II, largely because of inferred overexploitation (Vincent et al. 2011). Seahorses are commercially valued in the global trade of dried seahorses for traditional Chinese medicine, ornamental displays and curios (Evanson et al. 2011). Log book analyses and interviews with fishers in the study region indicated declines in populations of $H$. comes from direct exploitation and incidental catch in this study region and globally (Martin-Smith et al. 2004, Vincent et al. 2007, 2011, O'Donnell et al. 2010).

The present study was conducted at a time and place that was subject to a number of conservation initiatives, all of which had the potential to influence fishing effort (McClanahan \& Mangi 2001, Mangi et al. 2011), as well as the size and price of seahorses that were sold to local buyers (Lemieux \& Clarke 2009, Machumu \& Yakupitiyage 2013). First, several locally enforced, no-take marine reserves were established in the study area between 1996 and 2008 (see Fig. 1, Table S1 in the Supplement at www.int-res.com/articles/suppl/n027p095_supp.pdf). Second, starting in 2002, an association of smallscale fishers in the region also decided to adopt a $10 \mathrm{~cm}$ voluntary minimum size limit (MSL) for seahorses (Martin-Smith et al. 2004). Third, Philippines domestic legislation resulted in a ban on all seahorse take in May 2004, whereas the country had previously been one of the most important seahorse exporters in the world. The ban was a default national response to the global listing of all seahorses on Appendix II of the Convention on the International Trade of Endangered Species (CITES) in 2002, with implementation in 2004 (Vincent et al. 2011). Under an Appendix II listing, countries are permitted to export species as long as they can show that the trade is not adversely affecting wild populations (Reeve 2006). Philippines domestic legislation, however, imposes a national ban on the exploitation and trade of any CITES listed species, in a much more restrictive measure than CITES itself requires for those on Appendix II.

Given the inherent complexity of this multi-species fisheries, in an attempt to understand how temporal changes in the fisheries may have correlated to these conservation interventions, we monitored numerous different social and biological indicators in the landed catch of Hippocampus comes. First, we monitored the number of fishers who sold seahorses to buyers each day. In small-scale fisheries that use basic technology and are essentially human-powered, the number of fishers can be used as a proxy for fishing pressure or effort (Roberts et al. 2001, Hardman et al. 2013). Second, we monitored the number of seahorses sold as well as seahorse size, because both variables can act as an index of change of wild fish numbers (Graham et al. 2005) or indicate restraint by fishers. Changes in size distribution of fish populations (Graham et al. 2005) can help evaluate the sustainability of a fishery because larger fish tend to be more vulnerable to fishing pressure and are also more fecund (Shin et al. 2005, Dzyuba et al. 2006, Morgan \& Vincent 2013). Third, we examined the price of seahorses in relation to the size of seahorses and inflation rates, as well as the daily income of fishers in order to identify changing incentives for fishers (McClanahan 2010). Such incentives can affect the success or failure of conservation interventions, especially when poverty may be one of the drivers of unsustainable resource extraction (Geist \& Lambin 2002, Adams et al. 2004). 


\section{MATERIALS AND METHODS}

\section{Study area}

The present study took place on Danajon Bank, a double-barrier reef system in the central Philippines. The waters around the Philippines are among the most biodiverse and the most threatened in the world (Roberts et al. 2002). Danajon Bank covers $2350 \mathrm{~km}^{2}$, with over 28000 fishers in 234 coastal villages (Christie et al. 2006). Although this region was historically rich in natural resources, overfishing and dynamite and cyanide fishing have led to ecosystem degradation and fewer natural resources for a rapidly growing population $\left(3.0 \% \mathrm{yr}^{-1}\right.$ between 1995 and 2000) (Christie et al. 2006). These families are amongst the poorest in the Philippines (Green et al. 2003), with average family incomes less than $\$ 100$ USD $\mathrm{mo}^{-1}$ and average household sizes of 5.3 people (Christie et al. 2006).

We selected the 2 fishing communities that fishers reported had the largest catch of seahorses in this region (Meeuwig et al. 2003). These 2 locations, separated by about $12 \mathrm{~km}$ of ocean and reef, are hereafter called Sites A and B to protect the seahorse and preserve fishers' anonymity. Site A is located on a terrestrial island near the main island of Bohol, while Site B (with about twice as many households) is located on a coral atoll about $10 \mathrm{~km}$ from the main island. Both communities make their living from gillnet fisheries, gleaning, seaweed farming and lantern fishing. People in Site A also sell water to nearby communities, hold small agricultural plots and work as caretakers of aquaculture ponds (Hill 2011).

The lantern fishery that captures most seahorses is a multi-species, largely subsistence, open-access fishery. Fishers work at night, swimming and towing a boat; the boat either carries a low-slung kerosene lantern at the bow (until 2009) or fishers wear an improvised flashlight/headlamp (from 2009). When they see a potential catch, they swim down to a depth of about $5 \mathrm{~m}$ to spear food-fish or to capture invertebrates and seahorses by hand (Vincent et al. 2007). Fishers reported that they began capturing seahorses in 1966 at Site A, and the seahorse fishery spread to other regions in the 1970 s (A. C. J. Vincent \& M. G. Pajaro unpubl. data). Most seahorses are caught opportunistically (rather than targeted catch) but have been important to local fishers because they could be reliably sold to local buyers for cash (Vincent et al. 2007). Such local buyers, in turn, could sell these seahorses to exporters in Cebu City for international export (Evanson et al. 2011).

\section{Conservation interventions}

During our study period, fishing for seahorses may have been affected by 2 community-based conservation interventions and 1 national legal change.

A key intervention was the development of notake, community-based marine reserves in the region. From 1996 to 2008, Project Seahorse facilitated the implementation of 32 marine reserves in the Danajon Bank, with sizes ranging from 3.6 to 256 ha (Fig. 1). At least 9 of these marine reserves were created with the explicit objective of protecting seahorse habitat, among other objectives (authors' pers. obs.). Fishers would have worked near many such reserves. Specifically, 6 marine reserves were established within $5 \mathrm{~km}$ of Site A between 1996 and 2003 (Hansen et al. 2011). The 2 marine reserves that are immediately adjacent to Site A were assessed based on the Coastal Conservation and Education Foundation management rating system to be 'institutionalised with excellent management' (White et al. 2006, Samoilys et al. 2007). A marine reserve was also created adjacent to Site B in 2005. This reserve was assessed to be 'enforced and have good management' (White et al. 2006).

These reserves would be expected to benefit seahorse populations, and perhaps seahorse fisheries near the reserves. If reserves were effective, we would expect increases in seahorse catch and size starting from 1996 onwards at Site A, and from 2006 onwards

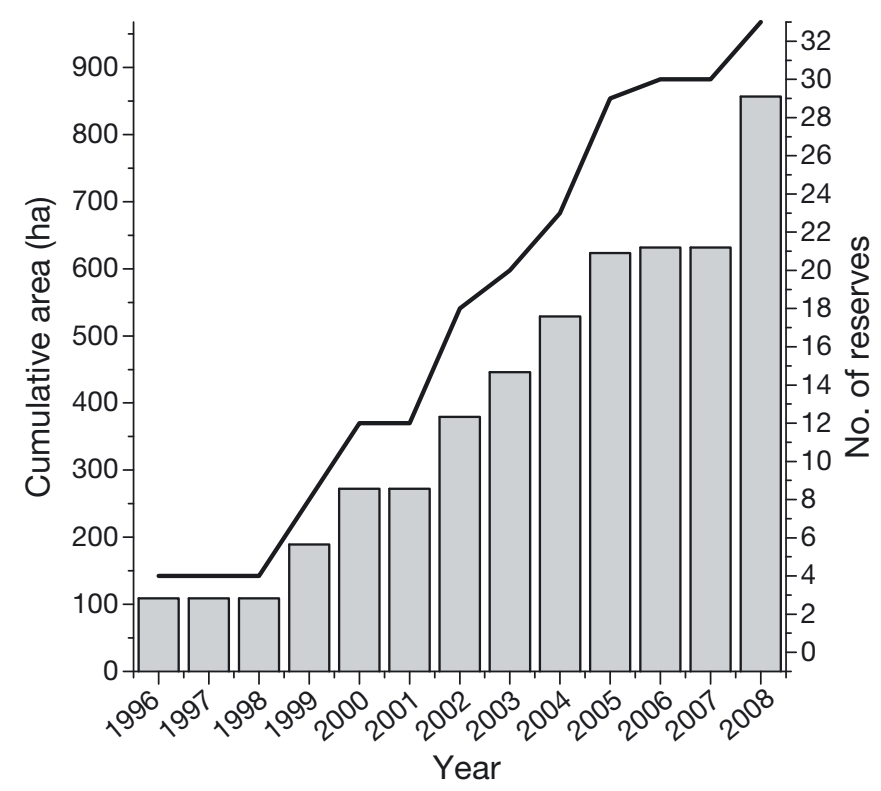

Fig. 1. Area (bars, left axis) and cumulative number (line, right axis) of Project Seahorse-assisted marine reserves over time 
at Site B. Our research on fish recovery in this suite of marine reserves shows that seahorses did increase slightly in size over this time period in areas immediately adjacent to marine reserves near Site A (Yasué et al. 2012). Seahorses have steep growth curves, short lifespans (1.3 to $3.0 \mathrm{yr}$ ) and quick generation times (Morgan \& Vincent 2013), so decreases in fishing pressure can quickly lead to increases in seahorse densities and the number of large seahorses. Larger seahorses are more vulnerable to fisheries because seahorses evade predators by camouflage, and larger seahorses sell for more money (Evanson et al. 2011).

Catch data are needed to supplement underwater research on recovery in marine reserves. Although seahorse fishers were employed to assist biologists in the visual underwater censuses for research on marine reserves (Yasué et al. 2012), seahorse sample sizes outside the reserves were simply too low (47 seahorses over $8 \mathrm{yr}$ surveying $2700 \mathrm{~m}^{2}$ at 3 sites) to determine changes in size, with the rarity of animals attesting to the great skill of - and vast expenditure of effort by - seahorse fishers.

A second key intervention was the adoption of a voluntary MSL restriction for seahorse fisheries. Between 2002 and 2004, Project Seahorse began leading community discussions and workshops to set a MSL of $10 \mathrm{~cm}$ for landed seahorses to protect against recruitment overfishing (Martin-Smith et al. 2004, Foster \& Vincent 2005). There was more community support at Site A than Site B (A. Nellas pers. obs.), presumably because of a much greater nongovernmental organisation (NGO) presence and stronger community organisation at Site A. If this community initiative had any effect on the fisheries, it would be likely evidenced by a decrease in the number of small seahorses $(<10 \mathrm{~cm})$ in the catch, especially in Site A, from 2003 onwards.

A third critical change was the implementation of a national ban on seahorse fishing, which took effect in May 2004. The Philippines legislation mandates an automatic national ban on extraction for any species listed on CITES Appendix II (which itself allows continued, sustainable, trade). However, the regulation is essentially not enforced in the study area and fishers continue to exploit seahorses within the study region (O'Donnell 2011). If this ban had some effect on the fisheries, the most parsimonious outcome would be declines in the number of fishers, daily catch and income as fishers switched out of this illegal activity. Because only few fishers would be willing to catch seahorses illegally, seahorse sizes and numbers sold per fisher per day would likely increase as seahorse populations recovered from the reduced fishing pressure. Prices of illegally sourced seahorses would likely increase due to reduced global supplies (Rivalan et al. 2007).

\section{Data collection}

The present study received human ethics research approval (H06-80484) from the University of British Columbia.

We hired and trained local assistants at the 2 study sites to record the daily seahorse catch at the main seahorse buyer in each of these communities. Each fisher was given a unique identifier code for research purposes. Only the local assistant and the Project Seahorse biologist could link the unique code to the fisher. Local assistants used calipers to measure the head and trunk length of seahorses as fishers came to sell seahorses to the buyer (Lourie \& Randall 2003). The head and trunk lengths were added together and then converted to height based on an empirical relationship (Height $=0.8472 \times$

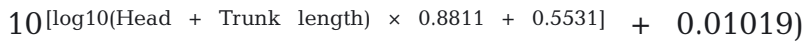
between head and trunk length and seahorse height (straight line from coronet to the tip of the tail) (Morgan \& Vincent 2013).

Beginning in 2002, local assistants also recorded the prices per seahorse (in Philippines Pesos, PHP) paid by the buyer to the fisher, and in 2005 local assistants began recording the fishing ground where each fisher worked.

Catch data were collected for half the year, during the dry season (March, April and May) and the wet season (August, September and October) for a total of 1607 and $865 \mathrm{~d}$ at Site A and Site B respectively. Logistic constraints and staffing limitations meant that data were obtained on a mean $( \pm \mathrm{SD})$ of $17 \pm 10 \mathrm{~d}$ $\mathrm{mo}^{-1}$ from 1996 to May 2004. No data were collected between 1999 and 2001 inclusive, and in the wet season of 2004. Data collection increased to a mean of 28 $\pm 3.0 \mathrm{~d} \mathrm{mo}^{-1}$ from the dry season of 2005 to the dry season of 2010 at both sites.

Even though the fisheries we examined became illegal from 2004 onward, it seems unlikely that fishers hid their catches from Project Seahorse because (1) Project Seahorse has worked on multiple projects within these communities for almost 2 decades and has built relationships with community members; (2) fishers are aware that Project Seahorse is not a law enforcement organisation; (3) the research assistant collecting the data was a local, known to the fishers; and (4) we knew the one reliable and consistent buyer in each of the communities. 


\section{Data analysis}

We conducted all data analyses on monthly aggregated values (means, unless otherwise stated).

Daily number of fishers and number of seahorses sold

We calculated the mean daily number of unique fishers per day (no. fishers $\mathrm{d}^{-1}$ ), the daily number of seahorses sold per fisher (seahorses fisher ${ }^{-1}$ ) as well as the mean daily number of seahorses caught by all fishers. For the mean daily sales of seahorses per fisher, we calculated means per day for all fishers who sold seahorses on a particular day and then calculated a mean of the daily averages for each month. For the mean daily sales of seahorses per day, we simply summed the catch for each day and then calculated a mean for the entire month. These data are limited in their validity as a measure of daily catch rate (per fisher per day, or per day) because we do not have data from fishers on days when (1) fishers did not go fishing, (2) fishers failed to catch seahorses despite targeting them, or (3) fishers caught seahorses but decided to stockpile them for a few days before bringing them to buyers.

\section{Size}

Because mean size does not adequately represent size distribution (with its management and conservation implications), we conducted analyses for size on the mean monthly seahorse height $(\mathrm{cm})$ as well as the 25th and 75th percentile seahorse heights $(\mathrm{cm})$.

\section{Price of seahorses}

Seahorse price is size-dependent, so we calculated a monthly mean 'weighted' price (PHP $\left.\mathrm{cm}^{-1}\right)$. Because this price is not adjusted for inflation, we refer to this as the nominal price. We used a similar averaging approach as above to calculate mean monthly prices.

To better understand the incentives that drive fishing and complement statistical analysis on changes in price over time, we also visually compared the price per seahorse for all non-aggregated (non-averaged) data to a national average consumer price index (CPI), cited here as the inflation-adjusted price. The CPI for the Philippines was obtained from the International Monetary Fund (IMF) World Economic
Outlook Database (www.imf.org/external/pubs/ft/ weo/2013/01/weodata/weoselser.aspx?c=566\&t=1).

Daily and seasonal income from seahorses

We calculated the mean daily income generated from the sales of seahorse per fisher $\left(\mathrm{PHP} \mathrm{d}^{-1}\right)$. Daily mean incomes were calculated in the same manner as the mean daily number of seahorses above. In addition to statistical analysis on the daily income from seahorses, we also present data on the total seasonal earnings (March, April, May [dry season] or August, September, October [wet season]) from seahorses for each unique fisher in each year (see Table 2) in order to examine annual seasonal income over time despite the fractured nature of the data (i.e. no data on some days, stockpiling). In addition to mean seasonal income, we also include the total number of fishers who sold seahorses for a given season, because seasonal data may be a better indicator (than daily number of fishers) of the total pool of fishers that go out and have the potential to spot and catch seahorses (while targeting other species). In this multi-species fishery, the decision to go fishing is likely unrelated to the abundance of seahorses (Vincent et al. 2007). Finally, we also calculated the income for the individual fisher who gained the greatest income from the seahorse fisheries for a given season, as well as the total income gained by all of the fishers within a season.

\section{Statistical analyses}

Independent and dependent variables

We conducted all statistical analyses on monthly aggregated values using the $\mathrm{R}$ statistical software ( $\mathrm{R}$ Development Core Team 2013). Although outliers were inspected to ensure that no single day or single seahorse size had a disproportionate effect on a particular monthly mean, we did not remove any apparent outliers because each point represented mean values sampled over a month from several different fishers, and thus 'extreme' high or low values likely represent real fluctuations in the observations. The independent variables in the present study were (1) year (1996 to 2010 at Site A, and 2005 to 2010 at Site B); (2) season (dry and wet); and (3) site (A and B). Season was included as an independent variable in the model because there is a breeding pulse during the wet season (Morgan \& Vincent 2013), and a fish- 
eries landings pulse in the dry season, partly due to lower turbidity and improved visibility (to detect seahorses) in the dry season (Morgan \& Vincent 2013).

The dependent variables in the statistical analyses were (1) the daily number of different fishers who sold seahorses to buyers; (2) the mean daily number of seahorses sold per fisher and total number of seahorses sold for all fishers per site; (3) mean monthly seahorse height, 75th and 25th percentile of seahorse height; (4) the price of seahorse (in PHP $\mathrm{cm}^{-1}$ ); and (5) the daily income generated from seahorses per fisher.

\section{Modelling approach}

We used generalised additive mixed effects (GAM) models (Gaussian distribution, identity link, library 'mgcv' in $\mathrm{R}_{i}$ Wood 2006) to examine the relationship between the independent variables (year, site and season) and the dependent variables. We used additive models rather than linear models because initial data inspection and residuals of linear models suggested that the relationships between year and the various dependent variables were not linear. For the additive models, year was fitted as a non-parametric smoother based on a cubic regression spline, and we included month as a random factor to account for monthly variation in the dependent variables.

\section{Model selection}

To identify minimum adequate models, we began with the 'full' model with all fixed effects. We were only able to include interaction terms between site and season because interaction terms between site and season and the year smoothing terms led to convergence errors. Thus, if visual inspection of data suggested that there may be significant interaction terms, we investigated the possible interaction terms by examining the figures that differentiated between sites and seasons, and also provide in the results the significance of models that were run separately for different sites or different season.

Based on examination of residual plots of the full models, we identified appropriate variance structures (varIdent or varFixed in R) for the models by comparing models with different variance structures using likelihood ratios tests $(\alpha<0.05)$. The variance structures accounted for heterogeneity (different spread of residuals) between years, months and/or sites. We also examined autocorrelation plots of residuals and included a lag 1 residual auto-correla- tion structure (corAR1 in R, library 'nlme') in the models to account for temporal autocorrelation. Although there was weak temporal autocorrelation in some of the data, adding an autocorrelation structure in the models did not improve the fit of any of the models nor did it reduce the autocorrelation in the model residuals.

To identify the minimum adequate model, we compared progressively simplified models (in terms of fixed effects or the interaction term) using likelihood ratios tests $(\alpha<0.05)$. We examined the difference in deviance when we sequentially removed each of the fixed effects (or interaction term) while retaining the other variables. Any variables that did not significantly improve the model (based on the deviance) were removed. When we compared different models with different random effects structures, we used restricted maximum likelihood (REML) estimates of variance components, but when we were comparing different fixed effects structures, we used maximum likelihood (ML) estimates of variance components (Crawley 2007).

The fixed effects in the final minimum adequate models are presented in the 'Results' section, and model summaries are presented in Table S2 in the Supplement at www.int-res.com/articles/suppl/n027 p095_supp.pdf.

\section{RESULTS}

\section{Fishing locations (2005 to 2010)}

Seahorses were caught in many locations. Fishers from Sites A and B identified 59 and 38 different seahorse fishing grounds, respectively, between 2005 and 2010. A total of 14 fishing grounds were cited as the source for more than $80 \%$ of the catch landed at Site A, and 12 fishing grounds were cited as sourcing $87 \%$ of the seahorse catch landed at Site B. Of these, 7 fishing grounds were common to fishers from both sites.

\section{Daily number of fishers}

The number of fishers selling seahorses to buyers each day appeared to increase from 2005 onwards (Table 1, Fig. 2). Throughout the study period, a total of at least 61 and 47 fishers sold seahorses to buyers at Sites A and B, respectively. There were more fishers capturing seahorses during the dry season than the wet season; the increase in the number of fishers was driven largely by increases in the wet season 
Table 1. Statistically significant fixed effects in the final generalized additive mixed-effects models. Detailed model summaries are provided in Table S2 in the Supplement at www.int-res.com/articles/suppl/n027p095_supp.pdf. Year: non-parametric cubic regression smoother for year, and month was included as a random factor in all models. PHP: Philippines Pesos (40 PHP = ca. 1 USD)

\begin{tabular}{|c|c|}
\hline Dependent variable & Independent variables \\
\hline Number of fishers $d^{-1}$ & Year, Season \\
\hline Seahorses sold fisher ${ }^{-1} \mathrm{~d}^{-1}$ & Year, Season, Site \\
\hline Total seahorses sold d $\mathrm{d}^{-1}$ & Season, Site \\
\hline Seahorse height (cm, average) & Year, Site \\
\hline Seahorse height ( $\mathrm{cm}, 75$ th percentile) & Year, Season, Site \\
\hline Seahorse height ( $\mathrm{cm}, 25$ th percentile) & Year, Site \\
\hline Seahorse price $\left(\mathrm{PHP} \mathrm{cm} \mathrm{cm}^{-1}\right)$ & Year, Season, Site \\
\hline Income (PHP fisher ${ }^{-1} \mathrm{~d}^{-1}$ ) & Year, Season, Site \\
\hline
\end{tabular}

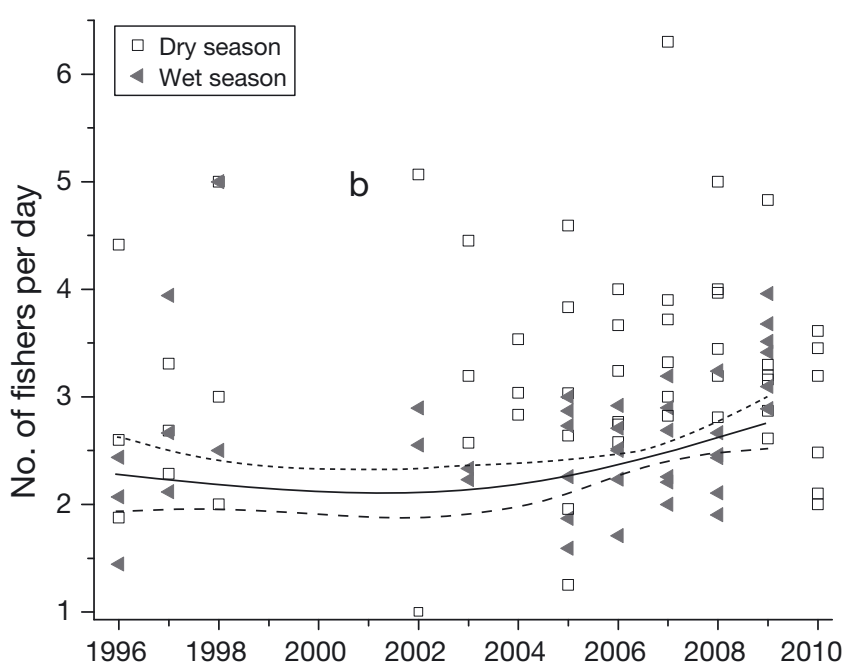

Fig. 2. Number of fishers selling seahorses to buyers per day between 1996 and 2010 at both Sites A and B. Each point represents $24 \pm 9.0$ sampling days at Site A and $28 \pm 3.0 \mathrm{~d}$ at Site B. Solid line: predicted value of the smoothing curve for year during the wet season (smoother for year was not statistically significant for the dry season); dotted lines: 2 standard errors from the fitted curve

(Fig. 2). When we ran 2 separate additive models for the dry and wet seasons, the smoother for year had a statistically significant effect on the number of fishers in the wet season $\left(F_{1.8}=5.4, \mathrm{p}=0.0107\right)$, but was marginally significant in the dry season $\left(F_{1}=3.5, \mathrm{p}=\right.$ 0.07 ). Site did not have a statistically significant effect on the daily number of fishers.

\section{Daily number of seahorses caught}

The daily number of seahorses caught per fisher increased until 2002 to 2004 and then decreased from 2005 at Site A, and from about 2006 at Site B. Visually, it appeared that this trend may have been driven by changes in Site A (Fig. 3). When we ran the GAM models for the sites separately, the year smoother was statistically significant for Site A $\left(F_{1.9}=58.4, \mathrm{p}<0.0001\right)$ but only marginal for Site B $\left(F_{1.6}=3.8, p=0.06\right)$. Fishers sold more seahorses per day in the dry season than in the wet season for both Site A and Site B (Table 1, Fig. 3), and the changes over time were larger in the dry season than in the wet season. Fishers sold more seahorses per day Site A than Site B.

The year smoother did not have a statistically significant effect $\left(F_{1.8}=1.7, \mathrm{p}=0.19\right)$ on the mean daily number of seahorses caught by all fishers combined. However, when we ran the GAM model separately for the 2 sites, the year smoother became statistically significant for both sites (Site A: $F_{1.9}=11.4, \mathrm{p}<$ 0.0001; Site B: $F_{1}=11.4, \mathrm{p}<0.00023$; Table 1, Fig. 4). The total daily number of seahorses sold increased and peaked in 2004 and declined from 2005 onwards for Site A. At Site B, the total catch peaked in 2007 and declined from 2008 onwards in the dry season, while in the wet season the total catch decreased until 2007 and then increased from 2008 onwards. Similar to above, the total daily catch for all fishers

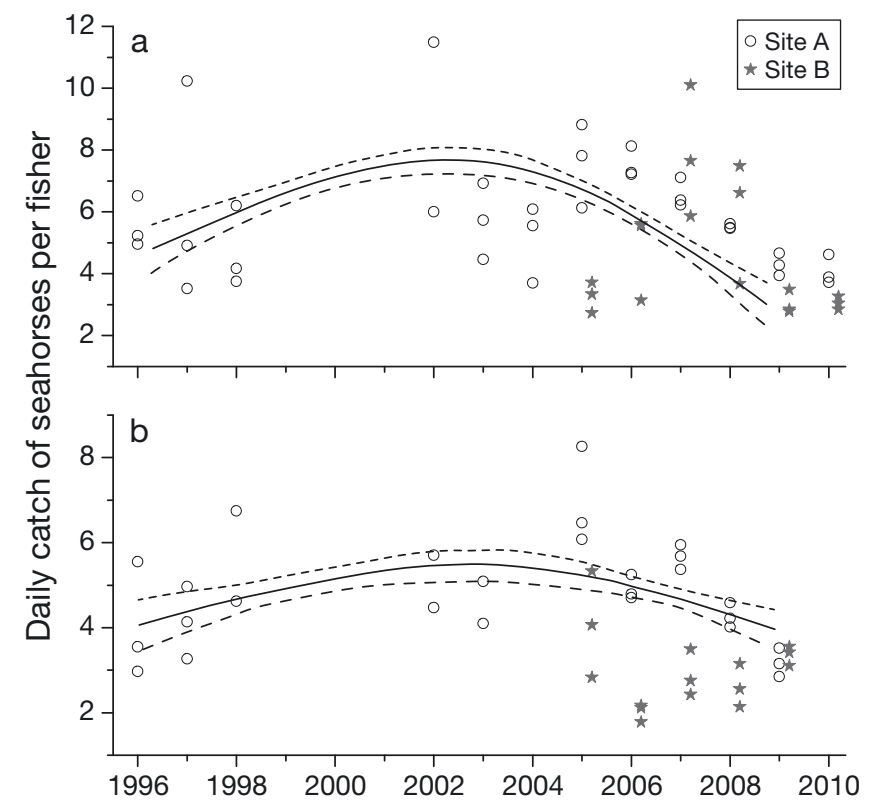

Fig. 3. Daily number of seahorses caught per fisher between 1996 and 2010 for the (a) dry and (b) wet seasons. Each point represents $408 \pm 266$ seahorses sampled over $24 \pm 9.0 \mathrm{~d}$ at Site A and $307 \pm 185$ seahorses sampled across $28 \pm 3.0 \mathrm{~d}$ at Site B. The 2002 high point at 11.5 seahorses represents 1636 seahorses caught over $30 \mathrm{~d}$ by 38 different fishers in April. Solid lines: predicted value of the smoothing curve for year at Site A (smoother for year was not statistically significant for Site B); dotted lines: 2 standard errors from the fitted curve 

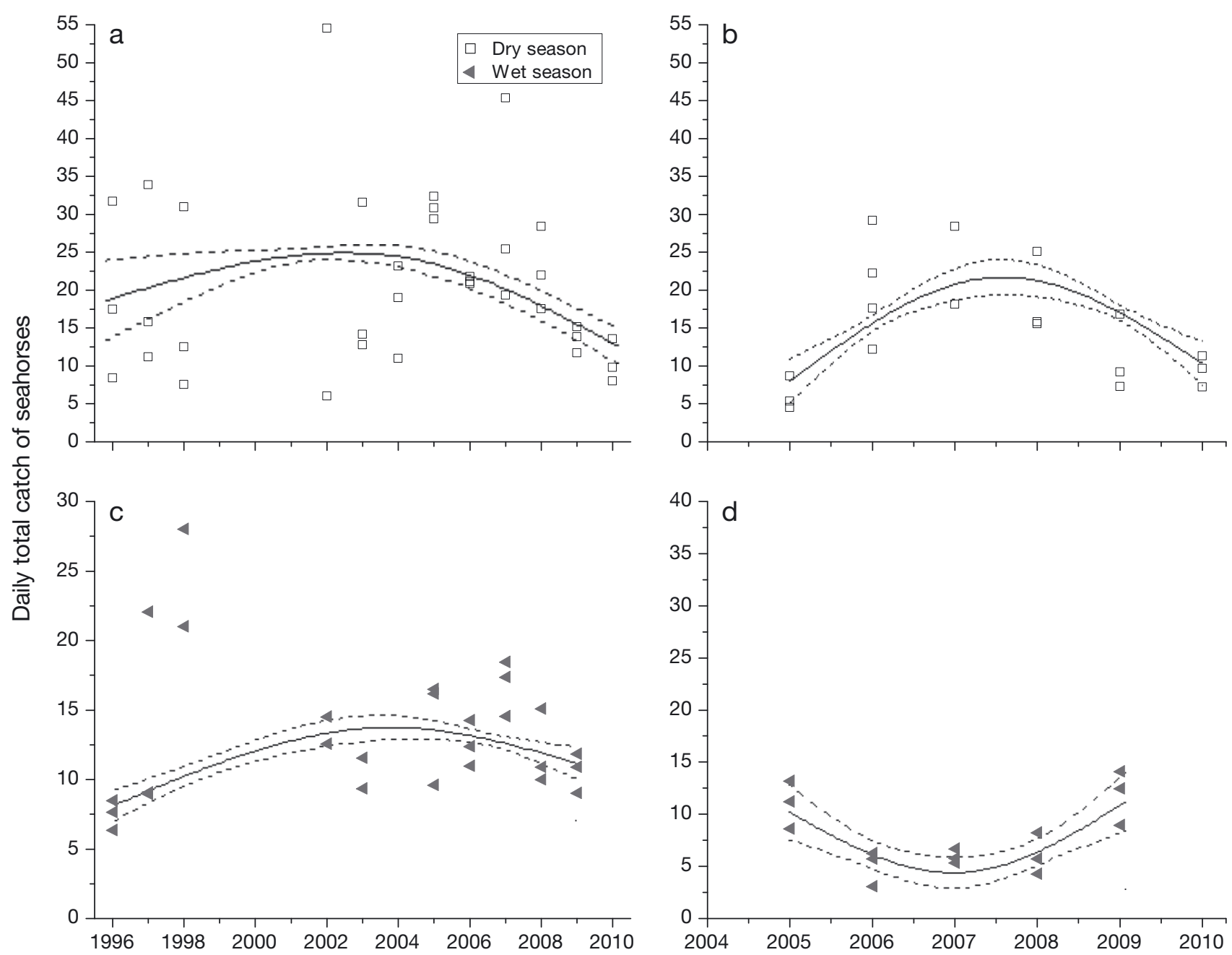

Fig. 4. Daily number of seahorses sold in total (a,c) between 1996 and 2010 at Site A and (b,d) between 2005 and 2010 at Site B in $(a, b)$ the dry season and $(c, d)$ the wet season. The 2002 high point at 55 seahorses represent the mean catch collected over 30 d by 38 different fishers in April. Solid lines: predicted value of the smoothing curve for year; dotted lines: 2 standard errors from the fitted curve

was greater in the dry season than in the wet season, and at Site A than at Site B.

\section{Seahorse size (height)}

Mean monthly seahorse size, 75th and 25th percentiles followed roughly similar trends over time for the 2 sites (Fig. 5). At Site A, seahorse sizes stayed the same or increased slightly from 1996 to 1998, decreased from 1998 to 2003, increased again from 2003 to 2006 and then decreased again slightly from 2006 onwards.

Inspection of stacked histograms for each year indicated that the earliest period (1996 to 1998; Fig. 6) had higher mean seahorse sizes as well as much larger seahorses in the largest quartile. Fishers were only selling very large seahorses (16 to $24 \mathrm{~cm}$; Fig. 6a). However, by 2002/2003, it appeared both that the mean seahorse size had dropped substantially and that fishers were catching smaller seahorses (4 to $18 \mathrm{~cm}$; Fig. 6b). However, from 2005 onwards, it appeared that at Site A fewer small seahorses $(<10 \mathrm{~cm})$ were no longer being sold to buyers, even though the mean seahorse size stayed low (11 to $16 \mathrm{~cm}$; Fig. 6c-f).

Site B appeared to have a very slight decrease over time from 2005 onwards. The largest (75th percentile) seahorses were bigger in the dry season than in the wet season, and seahorses were generally larger at Site A than Site B (Fig. 5). The difference in seahorse size between the 2 sites was 

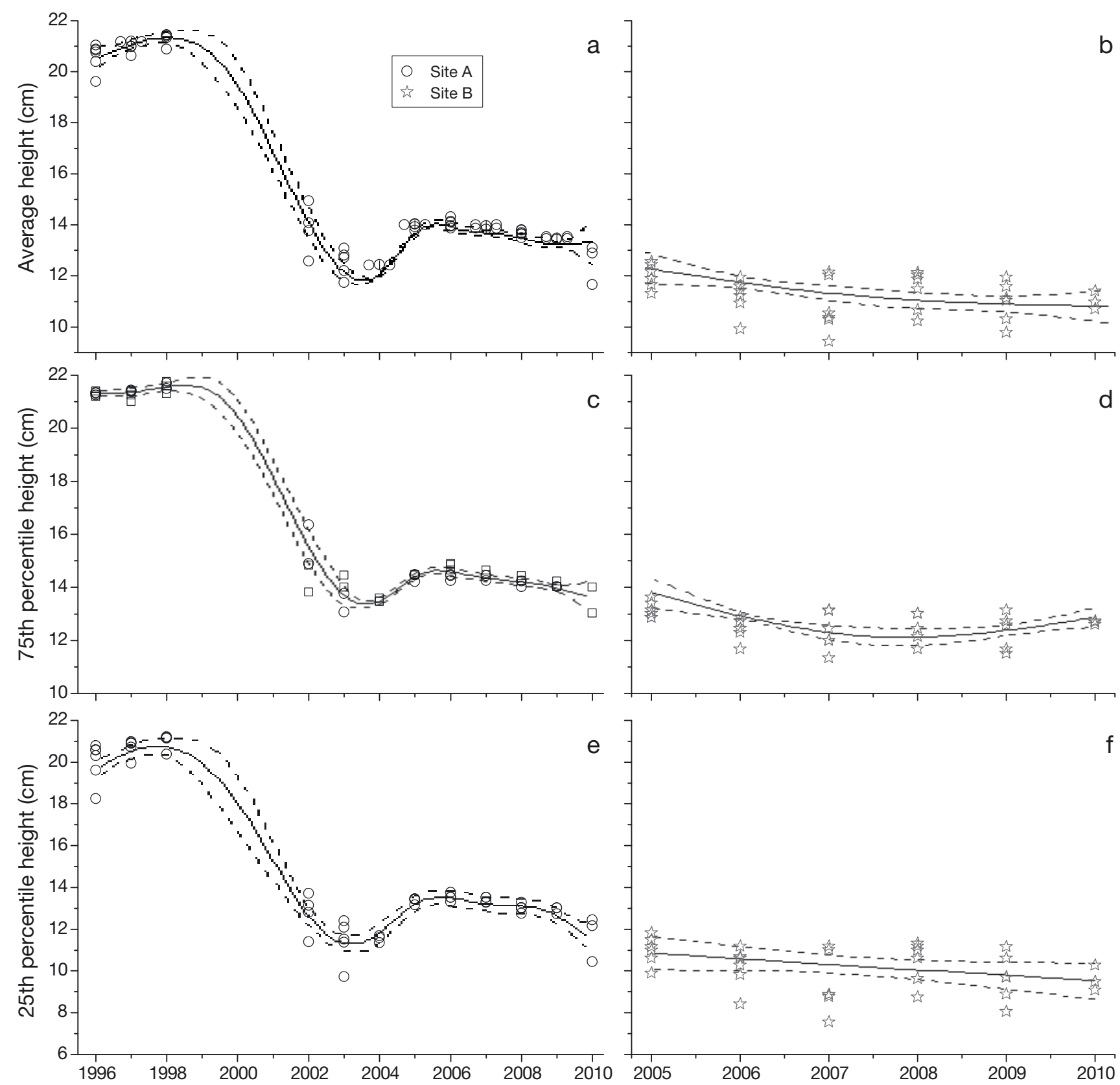

Fig. 5. (a,b) Monthly average, $(c, d) 75$ th percentile and $(e, f) 25$ th percentile seahorse heights of landed catch $(a, c, e)$ between 1996 and 2010 at Site A and $(b, d, f)$ between 2005 and 2010 at Site B. Solid lines: predicted value of the smoothing curve for year; dotted lines: 2 standard errors from the fitted curve

greatest for the seahorses in the 25th percentiles (in comparison to the mean or the 75 th percentile seahorses). This appeared to be due to the larger proportion of smaller-sized seahorses captured at Site B compared to Site A. In general, from 2005 onwards, the range of seahorse sizes captured at Site $B$ was much greater than the range of seahorse sizes captured at Site A (Figs. 5 to 7 ), and the size distributions of catch for Site B in 2006 and 2009 (4 to $20 \mathrm{~cm}$ ) were more similar to the size distribution of seahorses for Site A in 2003.

\section{Price of seahorses (inflation-adjusted and nominal price) and daily income (2002 to 2010)}

The unit price for seahorses of similar sizes stayed roughly the same in 2002 and 2005 at Site A 


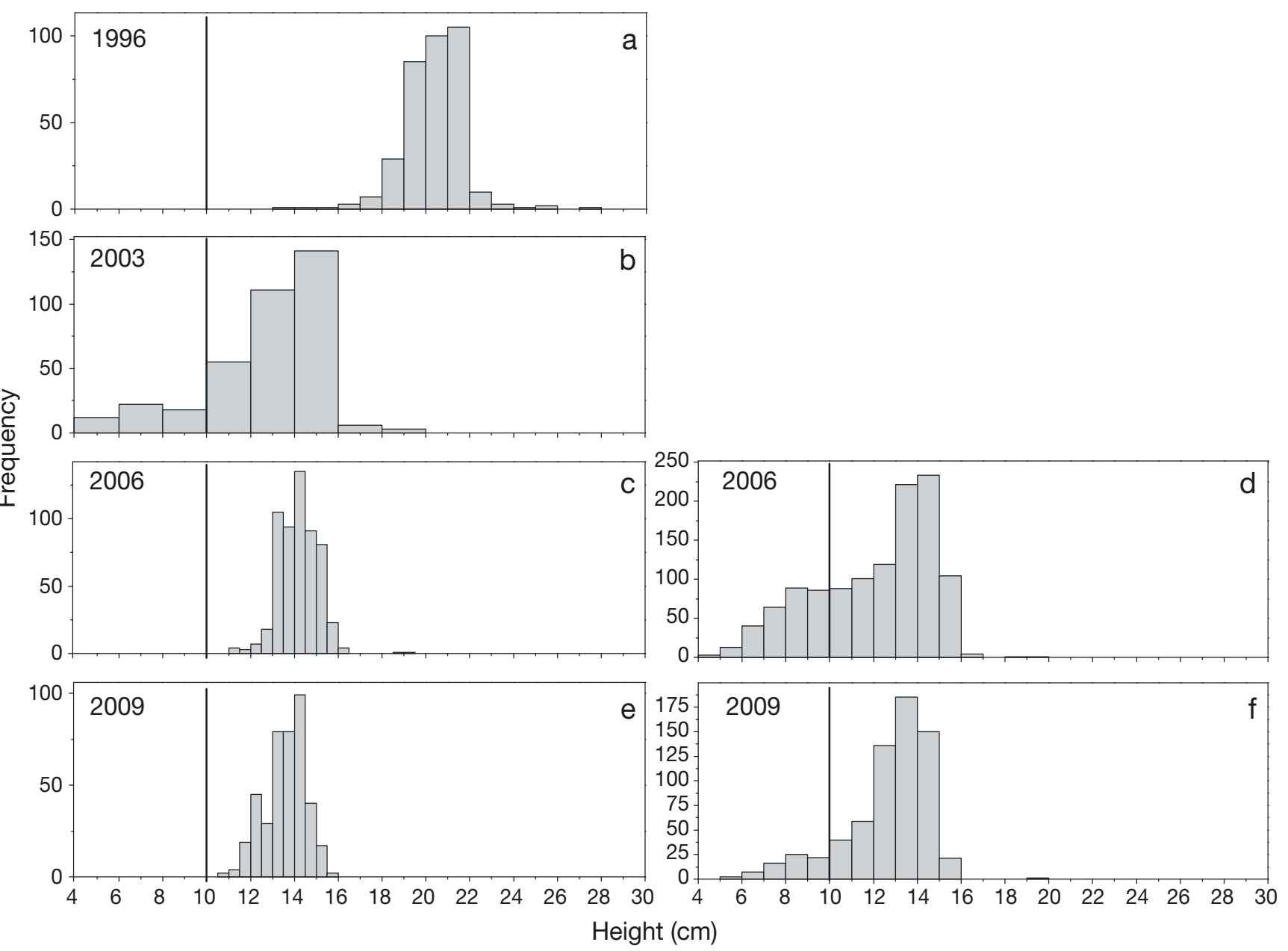

Fig. 6. Size distribution of seahorses in landed catch for (a) 1996, (b) 2003, (c,d) 2006 and (e,f) 2009, for (a,b,c,e) Site A and (d,f) Site B (2006 and 2009 only). In the interest of space, not all years that were monitored are displayed. However, as indicated in Fig. 5, the study period can be broken up into roughly 3 periods, each of which had similar seahorse size distributions (1996-1998, 2002-2004, 2005-2010). Black vertical line: the $10 \mathrm{~cm}$ voluntary minimum size limit implemented between 2002 and 2004

(Fig. 7a). However, seahorses were sold for more money in 2008 than in 2005, even when accounting for inflation (relative to CPI) (Fig. 7c). For example, the inflation-adjusted price for a $16 \mathrm{~cm}$ seahorse increased by $152 \%$ at Site A and $142 \%$ at Site B between 2005 and 2008 (Fig. 7c,d). This increase in price was greater (in terms of percent increase) for larger seahorses than for small seahorses between 2005 and 2008 (Fig. 7).

These increases in prices for individual seahorses were also reflected in the weighted nominal price of seahorses (PHP $\mathrm{cm}^{-1}$ ) at both sites. The increase in price began in 2006 and appeared to be steeper at Site A than Site B (Table 1, Fig. 8). The nominal price of seahorses was greater at Site A than Site B from 2008.
Finally, these increases in per unit and nominal price of seahorses were also reflected in the increase in calculated daily income for seahorse fishers. Visual inspection suggested that the effect of the year smoother differed between the 2 sites with a steeper increase in income at Site A than at Site B, though the year smoother was statistically significant for both sites (Site A: $F_{1.9}=142, \mathrm{p}<0.0001$; Site B: $F_{1.9}=9.4, \mathrm{p}<$ $0.0009 ;$ Fig. 9). The daily income increased throughout the monitored time period from 2002 onwards at Site A, and slightly from 2005 onwards at Site B (Fig. 9). Note that 2002 and 2005 were the years in which monitoring for daily income began in this study. For both sites, the daily income appeared to peak and then plateau in 2008. The daily income from seahorses was greater in the dry season than in the wet season. 


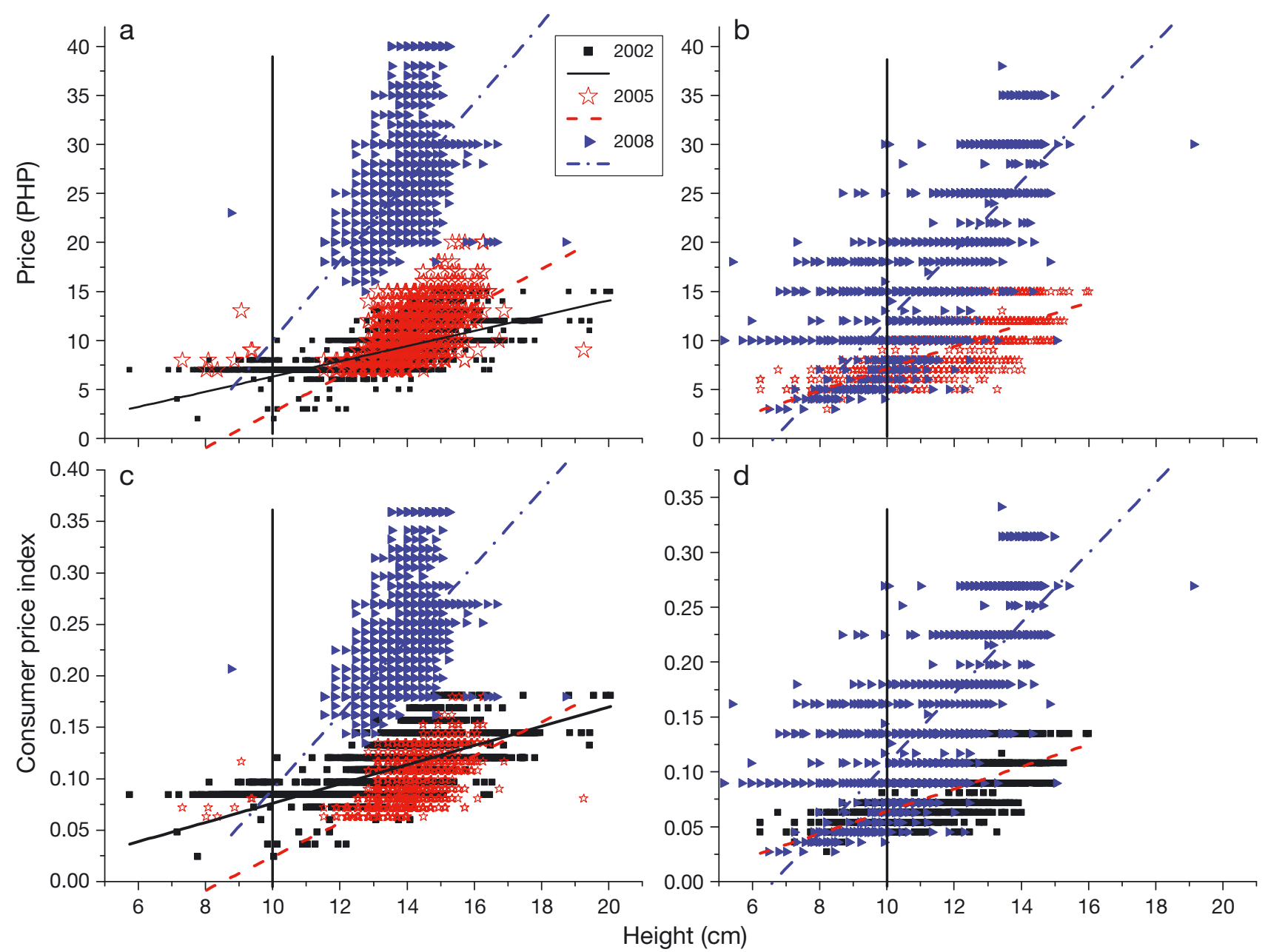

Fig. 7. Relationship between the size of seahorses and $(\mathrm{a}, \mathrm{b})$ price per seahorse (Philippines Pesos, PHP; 40 PHP = ca. 1 USD) and $(c, d)$ price relative to national inflation rates (Consumer Price Index) for 2 sites. Data collected across different years (2002, 2005 and 2008) are shown. Each point represents a landed seahorse. Regression lines are only for descriptive purposes and indicate lines of best fit. Black vertical line: the $10 \mathrm{~cm}$ voluntary minimum size limit

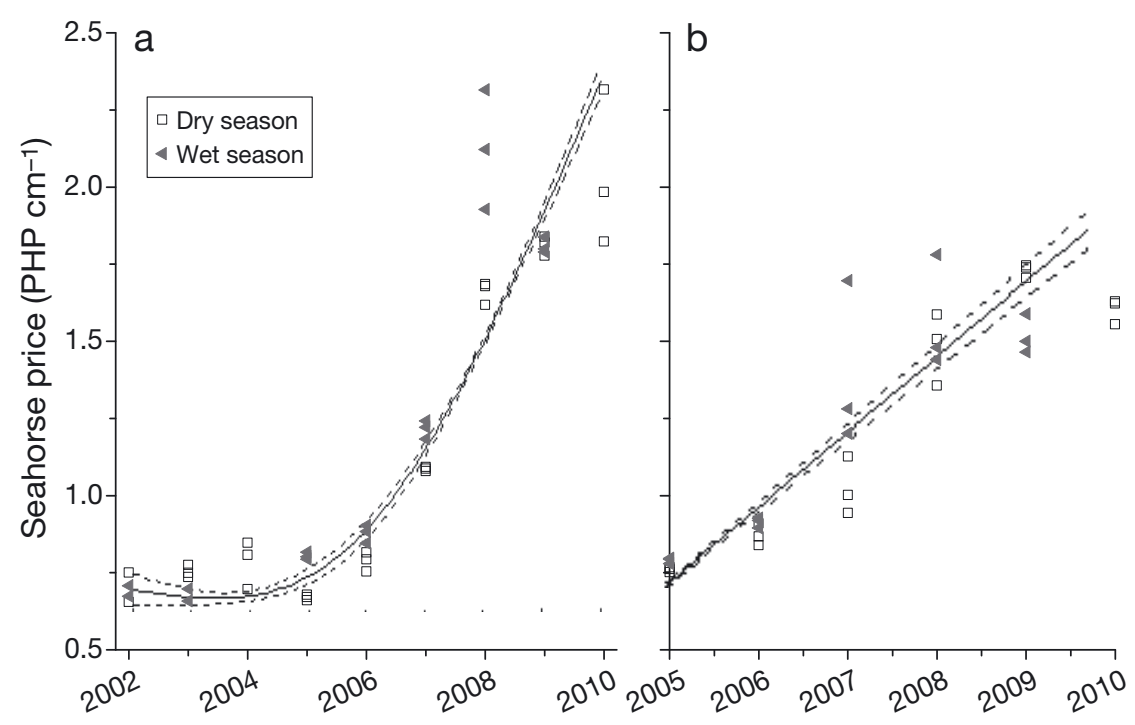

\section{Seasonal sales from seahorse catch (2002 to 2010)}

Overall, similar to the increase in daily income, the amount that an individual fisher earned from seahorses during our entire 6 mo monitoring period increased for both sites until 2008, and then plateaued.

Fig. 8. Nominal weighted seahorse price from (a) 2002 to 2010 for Site A and (b) 2005 to 2010 for Site B. Each point represents a mean monthly price. Solid lines: predicted value of the smoothing curve for year; dotted lines: 2 standard errors from the fitted curve 

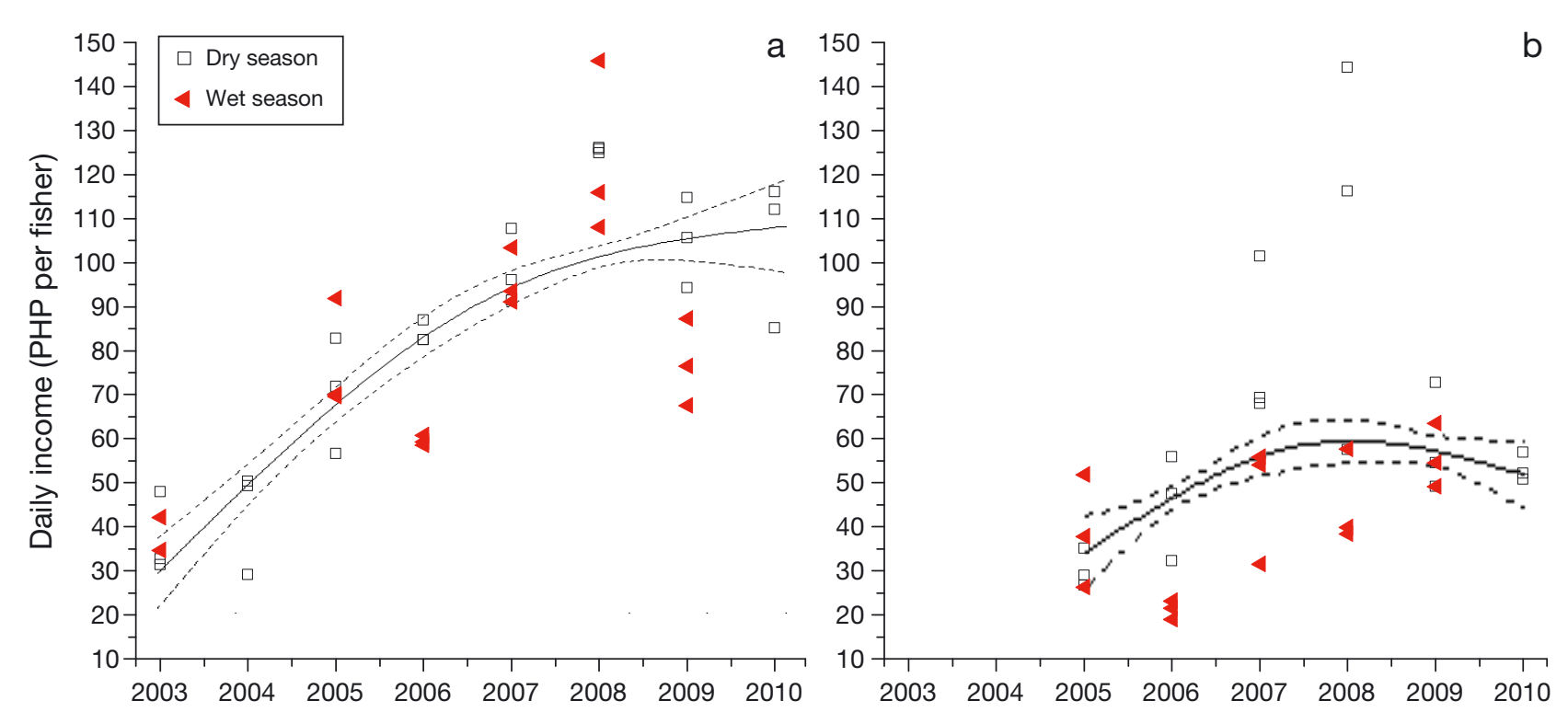

Fig. 9. Mean daily income per fisher from selling seahorses to buyers between 2002 and 2010 at (a) Site A and (b) Site B. Solid lines: predicted value of the smoothing curve for year; dotted lines: 2 standard errors from the fitted curve

Fishers varied greatly in the income they earned from seahorses in each season's catch. The majority of fishers appeared to be earning small amounts that likely represented about $5 \%$ of a (\$126 USD) monthly income in Bohol. However, a small number of fishers earned significant amounts, approaching a quarter of their monthly income. Although there were approximately 38 fishers at Site A selling seahorses in the dry season in 2002, $40 \%$ of the seasonal income from seahorses was accrued by 1 fisher (Table 2). Similarly, in the dry season of 2007, a single (different) fisher accounted for $30 \%$ of the total seasonal sales from seahorses. The income per season was greater at Site A than Site B, and in the dry season than the wet season (for both sites).

In contrast to the slight increase in the number of fishers selling seahorses per day in the wet season (Fig. 2), the number of different fishers selling seahorse per season did not appear to increase over time. This suggests that though the total pool of fishers stayed approximately the same, each fisher was spending more time or a greater number of days per month fishing.

\section{DISCUSSION}

Catch data allowed us to detect some correlations between seahorse landings and management and policy changes for some conservation interventions, although not for all. We detected that seahorse size in the catch increased with the agreement on minimum size limits. It also appears, perversely, that the number of fishers selling seahorses each day and the price per seahorse increased after the ban on exploitation was implemented. The dearth of exact matches between management transitions and seahorse landings is not surprising given the complexity of these natural and human systems (Table 3). The discrepancies between intention and outcome emphasise the difficulty in managing, monitoring and understanding these smallscale, multi-species fisheries. Nonetheless, our analyses of these fisheries indicate that national agencies should try to generate locally endorsed management plans rather than impose arbitrary and unenforced (or logistically unenforceable) bans on extraction.

The implementation of marine reserves - with their total area increasing throughout the study - serves as a backdrop for the 2 more punctuated events of a MSL restriction and a national ban on extraction. It is difficult to determine the role these marine reserves played, the effects of which might be felt quite slowly and only close to the marine reserves. The number of seahorses caught per fisher per day did increase in the late 1990s at Site A and might (or might not) be associated with the reserves. The decrease in sizes of seahorses during this time suggests that this increase in catch was not caused by a reserve effect but rather by fishers filtering less by size and catching more smaller-sized seahorses. However, other research 
Table 2. Summary statistics of the fisheries for the entire dry (March, April, May) and wet (September, October and November) seasons monitored from 2002 to 2010 for Sites A and B. Columns are (left to right): the mean \pm SD (Avg. fisher ${ }^{-1}$ ) of the seasonal earnings for each unique fisher in a season, the seasonal income for the fisher that earned the most for a given season (Max. fisher ${ }^{-1}$ ), the total number of fishers selling seahorses within a season, and the total income generated for all the fishers selling seahorses to the monitored buyers for each dry or wet season (Total). The final column indicates the total value of seahorses for both the monitored dry and wet season. To provide context, the average monthly income in Bohol in 2000 was \$126 USD mo ${ }^{-1}$ (Republic of the Philippines, National Statistics Office www.census.gov.ph/content/2009-average-annual-family-income-andexpenditure-province). Blank cells indicate no data

\begin{tabular}{|c|c|c|c|c|c|c|c|c|}
\hline \multirow{2}{*}{ Year } & \multicolumn{4}{|c|}{ Dry - } & \multicolumn{4}{|c|}{ Wet } \\
\hline & $\begin{array}{l}\text { Avg. fisher }{ }^{-1} \\
\text { (USD) }\end{array}$ & $\begin{array}{l}\text { Max. fisher } \\
\text { (USD) }\end{array}$ & $\begin{array}{l}\text { No. of } \\
\text { fishers }\end{array}$ & $\begin{array}{l}\text { Total } \\
\text { (USD) }\end{array}$ & $\begin{array}{l}\text { Avg. fisher }{ }^{-1} \\
\text { (USD) }\end{array}$ & $\begin{array}{l}\text { Max. fisher }{ }^{-1} \\
\text { (USD) }\end{array}$ & $\begin{array}{l}\text { No. of } \\
\text { fishers }\end{array}$ & $\begin{array}{l}\text { Total } \\
\text { (USD) }\end{array}$ \\
\hline \multicolumn{9}{|c|}{ Site A } \\
\hline 2002 & $7 \pm 14$ & 108 & 38 & 265 & $4 \pm 6$ & 23 & 35 & 149 \\
\hline 2003 & $4 \pm 12$ & 24 & 32 & 140 & $4 \pm 4$ & 16 & 22 & 81 \\
\hline 2004 & $6 \pm 16$ & 24 & 32 & 198 & & & & \\
\hline 2005 & $13 \pm 18$ & 68 & 33 & 448 & $10 \pm 13$ & 59 & 24 & 241 \\
\hline 2006 & $13 \pm 22$ & 51 & 31 & 390 & $8 \pm 11$ & 45 & 31 & 251 \\
\hline 2007 & $24 \pm 24$ & 111 & 35 & 826 & $14 \pm 15$ & 74 & 36 & 522 \\
\hline 2008 & $29 \pm 61$ & 141 & 39 & 1123 & $24 \pm 30$ & 108 & 31 & 755 \\
\hline 2009 & $21 \pm 59$ & 90 & 31 & 650 & $16 \pm 26$ & 94 & 31 & 500 \\
\hline 2010 & $27 \pm 65$ & 82 & & & & & & \\
\hline \multicolumn{9}{|l|}{ Site B } \\
\hline 2005 & $4 \pm 4$ & 20 & 20 & 70 & $4 \pm 7$ & 43 & 32 & 140 \\
\hline 2006 & $8 \pm 8$ & 29 & 32 & 244 & $3 \pm 3$ & 9 & 26 & 72 \\
\hline 2007 & $16 \pm 29$ & 124 & 26 & 410 & $5 \pm 4$ & 15 & 33 & 154 \\
\hline 2008 & $29 \pm 35$ & 101 & 22 & 628 & $7 \pm 6$ & 19 & 29 & 213 \\
\hline 2009 & $20 \pm 14$ & 41 & 20 & 404 & $12 \pm 13$ & 40 & 27 & 335 \\
\hline 2010 & $15 \pm 13$ & 38 & 20 & 303 & & & & \\
\hline
\end{tabular}

Table 3. Most parsimonious predictions of how the 3 conservation interventions would affect dependent variables measured in this study. 'Actual trend' indicates the changes over time observed in each of the sites and seasons. SH: seahorse; MSL: minimum size limit; PHP: Philippines Pesos. Years in column headings represent when a particular intervention began. Given rapid seahorse growth rates and generation times, we would expect changes in dependent variables to occur the following year

\begin{tabular}{|c|c|c|c|c|c|}
\hline Intervention & $\begin{array}{l}\text { Marine reserves } \\
\quad \text { (from 1998) }\end{array}$ & $\begin{array}{c}\text { Predictions } \\
10 \mathrm{~cm} \mathrm{MSL} \\
(2002-2004)\end{array}$ & $\begin{array}{c}\text { National ban } \\
\text { (May 2004) }\end{array}$ & Actual trend & Fig. \\
\hline No. of fishers & No change & No change & Large decrease & Slight increase from 2005, wet season & 2 \\
\hline $\begin{array}{l}\text { No. of SH sold } \\
\left(\text { total d }{ }^{-1}\right)\end{array}$ & $\begin{array}{l}\text { Increase (if } \\
\text { spillover is } \\
\text { working) }\end{array}$ & $\begin{array}{l}\text { Slight decrease } \\
\text { (of } \mathrm{SH}<10 \mathrm{~cm} \text { ) }\end{array}$ & Large decrease & $\begin{array}{l}\text { Slight increase at Site A from 1996-2003, then } \\
\text { decreased from } 2005 \text { onwards } \\
\text { Increased at Site B until } 2007 \text {, then decreased from } \\
2007 \text { onwards in dry season. In wet season, decrease } \\
\text { until } 2007 \text { then increase from } 2007 \text { onwards }\end{array}$ & 4 \\
\hline $\begin{array}{l}\text { SH size in } \\
\text { the catch }\end{array}$ & $\begin{array}{l}\text { Increase (especially } \\
\text { maximum size) }\end{array}$ & Increase & Increase & $\begin{array}{l}\text { Slight increase } 1996-1998 \\
\text { Decrease 1998-2003 } \\
\text { Slight increase } 2003-2006 \\
\text { Decrease in small <10 cm SH for Site A only from } 2005 \\
\text { Slight decrease } 2006 \text { onwards }\end{array}$ & 5,6 \\
\hline $\begin{array}{l}\text { Price } \\
\left(\mathrm{PHP} \mathrm{cm}^{-1}\right)^{\mathrm{a}}\end{array}$ & No change & No change & $\begin{array}{l}\text { Increase (for illegal } \\
\text { trade because } \\
\text { catches declined) }\end{array}$ & $\begin{array}{l}\text { Increase from } 2005 \\
\text { Steeper increase at Site A than at Site B }\end{array}$ & 7,8 \\
\hline Daily income & Small increase & $\begin{array}{l}\text { Small decrease } \\
\text { initially (because } \\
\text { of lost income } \\
\text { from small SH) }\end{array}$ & $\begin{array}{l}\text { Increase (for } \\
\text { people that still } \\
\text { fish illegally) }\end{array}$ & Increased at both sites until 2008, then plateaued & 9 \\
\hline
\end{tabular}


indicated that size of seahorses increased inside the reserves (Yasué et al. 2012). This study nonetheless suggests that these larger seahorses were not spilling out of the reserves at a rate that affected landings.

The promotion in 2002 of a voluntary MSL of $10 \mathrm{~cm}$ - intended to ensure that seahorses were able to reproduce before being fished - may have had some effect. The number of seahorses sold per fisher per day stabilised from 2002, even while the total number sold per day continued to increase. The mean size of the seahorses in trade also increased from 2003, with an apparent and abrupt selection for seahorses larger than $10 \mathrm{~cm}$. Fishers clearly do filter for size: underwater visual censuses in this region that employed seahorse fishers between 2002 and 2008 indicated that $15 \%$ of seahorses were $<10 \mathrm{~cm}$ in height (Yasué et al. 2012), whereas between 2003 and 2008 only $2 \%$ of landed seahorses were less than $10 \mathrm{~cm}$ at Site A. The effect was greater at Site A than Site B, probably because Project Seahorse was much more active at Site A, both in terms of communications and monitoring. Consequently, the community appears to have complied with this MSL to a much greater extent than at Site B. MSLs are a well-tested approach to managing fisheries that are data limited, largely because they do not require elaborate assessment or enforcement (Foster \& Vincent 2005). This is probably because in contrast to large seahorses, the opportunity cost of leaving small seahorses is relatively small (Martin-Smith et al. 2004). In comparison to this small opportunity cost, since the minimum size limit was part of a community agreement, individuals going against this agreement and selling seahorses may incur a greater cost in terms of community social capital (Pretty \& Smith 2004).

The national ban on seahorse extraction in 2004 correlated with several changes in the seahorse fishery, some of them surprising. Given that there were more fishers selling seahorses each day after the ban than before, it seems likely that the decline in the number of seahorses per fisher and in total take were a consequence of overfishing rather than of abstinence from fishing. On the other hand, mean size of seahorses in trade increased from 2004 to 2005 at Site A, albeit with a subsequent slow decline. Given the increase in the number of fishers selling seahorses each day and the much greater increase in size for 25th percentile (rather than the 75th percentile) seahorses, this increase in mean size is more likely to be related to fishers catching fewer small seahorses due to the MSL rather than increased mean sizes due to the national ban and the resulting recovery of the populations. The sharp price in- creases after the ban, particularly for larger seahorses as well as increased catch per day from 2002 to 2004, helped to explain why daily income per fisher from seahorses increased until 2008. This price increase may also reflect a shortage of seahorses in trade at a national or global scale, regardless of local rates of extraction. Economically, in terms of daily income per fisher, after 2008 it appeared that the higher prices for seahorses (PHP cm${ }^{-1}$ ) were just able to compensate for the increased number of fishers selling seahorses each day, the lower daily catch and the progressively smaller seahorses. Ecologically, however, this is a conservation concern.

Our study suggests that in order for domestic regulations to be effective, regulations must have legitimacy in the eyes of the local people who are exploiting the resources (Western \& Wright 1994, Naylor 2005). Taken together, it appears that the local MSL affected fisher behaviour, whereas the national ban had little traction with the fishers. These 2 management actions differed in their provenance and the extent to which they were communicated. The MSL was much discussed and eventually adopted by a local alliance of small-scale fishers as a precautionary measure that still allowed continued seahorse extraction. The national ban on seahorse extraction was an automatic result of a global decision to manage seahorse exports. It had no local backing, not even from Project Seahorse as catalysts for conservation in the region, and there were no evident direct communications from government of this change. Community support for interventions becomes especially important in regions where there is limited enforcement, or if the illegal trade is especially difficult to detect (Western \& Wright 1994). Thus, fishers apparently continued to extract seahorses despite their limited dependency on income from this species, and its declining financial reward. Interviews with seahorse fishers in 1995 suggested that fishers were generating one-third of their annual income from seahorse fishing and up to $100 \%$ of their income in the peak season (A. C. J. Vincent \& M. G. Pajaro unpubl. data). In 2009, even in the most profitable months fishers only made a small fraction of their annual income.

A national ban on taking seahorses was always likely to be problematic in a context where there was high, continued global demand for seahorses. Changes in supplies as global markets adjust to export controls and changes in prices for seahorses would certainly be expected to affect how fishers in Philippine villages responded to an arbitrary national ban. We know that supplies continued to flow from the Philippines to Hong Kong in 2006, at higher 
prices (Lam et al. in press). It is notable that the arbitrary national ban on extraction of the humpback wrasse Cheilinus undulatus in the Philippines after it was listed on CITES Appendix II was also linked to rampant illegal trade (Chen \& Justin 2009, Poh \& Fanning 2012).

Our study casts into sharp relief the enormous difficulties in attributing changes in catch landings for small-scale fisheries to particular management interventions. Ours is the most extensive study of a seahorse fishery to date, both in the number of landed animals it embraces and in the duration of the study. Nonetheless, we find it difficult to discern how management and policy changes affected landings. A key challenge to understanding this fishery is that these seahorses are only one species in a highly diverse multi-species fishery, in which most marine life that a fisher encounters has value and will be extracted. The decision on whether to fish on a particular day, where to fish, what taxa to seek most energetically, and what taxa to take is made (and continuously revised) by the fisher based on myriad of socio-economic or ecological variables that may be unrelated to seahorse densities (Vincent et al. 2007). The decisions of fishers to target particular (nonseahorse) fish will influence catch rate of seahorses because seahorses are cryptic enough that a fisher focusing on mid-water taxa may or may not spot them when swimming very near them (Vincent et al. 2007). Another factor contributing to the challenge of understanding this fishery and how it has been affected by management interventions is the sheer number of fishing grounds where seahorses were caught - and of fishers who caught them.

Our work helps in exploring the differences in management between industrial and subsistence fisheries. In industrial fisheries, there is an assumption that key changes in laws, such as a national ban on a particular gear or fisheries, would influence the decision of fishers (Pondella \& Allen 2008). In places such as our study area, however, where there is no enforcement and fishers may be unaware of the national ban (Christie et al. 2011), the effect of national management restrictions may be very muted at best. Moreover, one can assume that fishers' decisions to fish in industrial single-species fisheries can be predicted using economic models based on variables such as catch per unit effort, price or daily income from the targeted catch (Tidd et al. 2011). In contrast, these types of variables may have little impact on subsistence fishers in multi-species fisheries whose take depends on what they happen to encounter. Indeed, rare or threatened species caught in such contexts or even as bycatch in industrial fisheries (Vincent et al. 2011) may be driven to local extinction by fishers who are targeting other, more abundant species (Branch et al. 2013). The situation may, indeed, be even more complex as most fishing families also draw their support from other employment in an unpredictable mosaic of incomeearning opportunities (Hill 2011); fisheries regulations may play little part in their decisions.

This study has demonstrated how measuring a wider range of biological and social variables intensively and over a long period of time can allow us to cross-validate different data and gain insight into a complex fishery. In addition, this study has allowed us to critically assess some of the key assumptions of fisheries management (Tidd et al. 2011, Hilborn \& Hilborn 2012) through a small-scale, multi-species lens. Future studies could consider examining from a broader spatial scale the decisions and prices paid by regional buyers and sellers of seahorses, as well as a more detailed assessment of how the decisions made by fishers to target different (no-seahorse) fish translates to different catches of seahorses.

The reality is that landings data, flawed and inconclusive as they are, are often the best available information for exploited marine fish of conservation concern. Working on the basis that all advice is imperfect (Johannes 1998), our findings here should be deployed to encourage national authorities to manage seahorse exploitation for sustainability (e.g. through MSLs) rather than hoping such fisheries have ended. This advice is particularly relevant in the current context, when a number of CITES member countries have recently opted to ban seahorse catch or exports in lieu of managing their exports for sustainability as they are required to do under the Convention.

Acknowledgements. This is a contribution from Project Seahorse. The authors thank the John G. Shedd Aquarium and Guylian Chocolates, Belgium, for their support through partnerships in marine conservation with Project Seahorse. We are grateful to friends at Project Seahorse Foundation in the Philippines: Armi May Torrechilla-Guzman, Fermina Genson, Ron Kirby Manit, Jesus Rey Dongallo, Edwin Dumalagan Jr, Merly Ravelo, Rosemarie Apurado and also to the local research assistants Sylvia Cabildo, Lando Largo, Ana Largo for expert data collection, logistic support and sharing their extensive experiences in these communities. We are also grateful to Kerrie O'Donnell for comments on previous drafts and helpful suggestions throughout the process. Thanks to M.Y.'s interdisciplinary colleagues at Quest University Canada: Doug Munroe, Tamara Trafton and Megan Bulloch, who commented on previous drafts or helped with analysis. We are also grateful to 2 anonymous reviewers whose detailed comments improved the manuscript. 


\section{LITERATURE CITED}

Adams WM, Aveling R, Brockington D, Dickson B and others (2004) Biodiversity conservation and the eradication of poverty. Science 306:1146-1149

Branch TA, Lobo AS, Purcell SW (2013) Opportunistic exploitation: an overlooked pathway to extinction. Trends Ecol Evol 28:409-413

Castilla JC, Defeo O (2005) Paradigm shifts needed for world fisheries. Science 309:1324-1325

Chen JNS, Justin SR (2009) Regulating the Humphead wrasse (Cheilinus undulatus) trade in Sabah, Malaysia. Ambio 38:123-125

Christie P, Armada NB, White AT, Gulayan AM, de Dios HHY (2006) Coastal environmental and fisheries profile of Danajon Bank, Bohol, Philippines. Fisheries Improved for Sustainable Harvest (FISH) Project, Cebu City

Christie P, Oracion EG, Eisma-Osorio L (2011) Impacts of the CITES listing of seahorses on the status of the species and on human well-being in the Philippines. FAO Fisheries and Aquaculture Circular, United Nations, Rome

Crawley MJ (2007) The R Book. John Wiley \& Sons, Chichester

> Dulvy NK, Polunin NVC (2004) Using informal knowledge to infer human-induced rarity of a conspicuous reef fish. Anim Conserv 7:365-374

> Dzyuba B, Van Look JW, Cliffe A, Koldewey HJ, Holt WV (2006) Effect of parental age and associated size on fecundity, growth and survival in the yellow seahorse Hippocampus kuda. J Exp Biol 209:3055-3061

Evanson M, Foster SJ, Wiswedel S, Vincent ACJ (2011) Tracking the international trade of seahorses (Hippocampus species). Fish Cent Res Rep Vol 19, No. 2. University of British Columbia, Vancouver

Foster SJ, Vincent ACJ (2005) Enhancing sustainability of the international trade in seahorses with a single minimum size limit. Conserv Biol 19:1044-1050

Geist HJ, Lambin EF (2002) Proximate causes and underlying driving forces of tropical deforestation. Bioscience 52:143-150

Gillis DM, Peterman RM, Tyler AV (1993) Movement dynamics in a fishery: application of the ideal free distribution to spatial allocation of effort. Can J Fish Aquat Sci 50:323-333

Graham NAJ, Dulvy NK, Jennings S, Polunin NVC (2005) Size-spectra as indicators of the effects of fishing on coral reef fish assemblages. Coral Reefs 24:118-124

Green SJ, White AT, Flores JO, Carreon MF III, Sia AE (2003) Philippine fisheries in crisis: a framework for management. Coastal Resource Management Project of the Department of Environment and Natural Resources, Cebu City

> Hansen GJA, Ban NC, Jones ML, Kaufman L, Panes HM, Yasué M, Vincent ACJ (2011) Hindsight in marine protected area selection: a comparison of ecological representation arising from opportunistic and systematic approaches. Biol Conserv 144:1866-1875

Hardman ER, Edwards AJ, Raffin JSJ (2013) The seine-net fishery of Rodrigues Island, western Indian Ocean: Is it sustainable or in terminal decline? Fish Res 139:35-42

Hilborn R, Hilborn U (2012) Overfishing: What everyone needs to know. Oxford University Press, Oxford

Hill NAO (2011) Livelihood diversification for conservation: interactions between seaweed farming and fishing in Danajon Bank, central Philippines. PhD dissertation,
Imperial College London, University of London

Hudson E, Mace G (1996) Marine fish and the IUCN Red List of threatened animals. Zoological Society of London

Johannes RE (1998) The case for data-less marine resource management: examples from tropical nearshore finfisheries. Trends Ecol Evol 13:243-246

Lam J, Koldewey H, Yasué M, Vincent ACJ (in press) Comparing interview and trade data in assessing changes in the seahorse Hippocampus spp. trade following CITES listing. Oryx

Lemieux AM, Clarke RV (2009) The international ban on ivory sale and its effects on elephant poaching in Africa. Br J Criminol 49:451-471

Lourie SA, Randall JA (2003) A new pygmy seahorse, Hippocampus denise (Teleostei: Syngnathidae) from the Indo-Pacific. Zool Stud 42:284-291

> Ludwig D, Hilborn R, Walters C (1993) Uncertainty, resource exploitation, and conservation: lessons from history. Science 260:17-36

> Machumu ME, Yakupitiyage A (2013) Effectiveness of marine protected areas in managing the drivers of ecosystem change: a case of Mnazi Bay Marine Park, Tanzania. Ambio 42:369-380

> Mangi SC, Rodwell LD, Hattam C (2011) Assessing the impacts of establishing MPAs on fishermen and fish merchants: the case of Lyme Bay, UK. Ambio 40:457-468

Martin-Smith KM, Samoilys MA, Meeuwig JJ, Vincent ACJ (2004) Collaborative development of management options for an artisanal fishery for seahorses in the central Philippines. Ocean Coast Manag 47:165-193

McClanahan TR (2010) Effects of fisheries closures and gear restrictions on fishing income in a Kenyan Coral Reef. Conserv Biol 24:1519-1528

- McClanahan TR, Mangi S (2001) The effect of a closed area and beach seine exclusion on coral reef fish catches. Fish Manag Ecol 8:107-121

McClanahan TR, Graham NAJ, Maina J, Chabanet P, Bruggemann JH, Polunin NVC (2007) Influence of instantaneous variation on estimates of coral reef fish populations and communities. Mar Ecol Prog Ser 340:221-234

Meeuwig JJ, Samoilys MA, Eradieno J, Hall H (2003) Fishers' perceptions on the seahorse fishery in central Philippines: interactive approaches and an evaluation of results. In: Haggan N, Brignall C, Wood L (eds) Putting Fishers' Knowledge to Work: Conference Proceedings. Fisheries Centre Research Reports, Vol 11. University of British Columbia, Vancouver, p 208-223

> Morgan SK, Vincent ACJ (2013) Life-history reference points for management of an exploited tropical seahorse. Mar Freshw Res 64:185-200

> Murphy HM, Jenkins GP (2010) Observation methods used in marine spatial monitoring of fishes and associated habitats: a review. Mar Freshw Res 61:236-252

Naylor RT (2005) The underworld of ivory. Crime Law Soc Change 42:261-296

Norse EA, Crowder LB (eds) (2005) Marine conservation biology: the science of maintaining the sea's biodiversity. Island Press, Washington, DC

O'Donnell KP (2011) Uniting historic perspectives, human behaviour, and habitat use to assess the future for overfished seahorses. PhD dissertation, University of British Columbia, Vancouver

O'Donnell KP, Pajaro MG, Vincent ACJ (2010) How does the accuracy of fisher knowledge affect seahorse conservation status? Anim Conserv 13:526-533 
Pauly D, Hilborn R, Branch TA (2013) Fisheries: Does catch reflect abundance? Nature 494:303-306

Poh TM, Fanning LM (2012) Tackling illegal, unregulated, and unreported trade towards Humphead wrasse (Cheilinus undulatus) recovery in Sabah, Malaysia. Mar Policy 36:696-702

Polidoro B, Livingstone SR, Carpenter KE, Hutchinson B and others (2008) Status of the world's marine species. IUCN Red List of Threatened Species, Species Survival Commission, Gland

Pondella DJ, Allen LG (2008) The decline and recovery of four predatory fishes from the Southern California Bight. Mar Biol 154:307-313

Pretty J, Smith D (2004) Social capital in biodiversity conservation and management. Conserv Biol 18:631-638

R Development Core Team (2013) R: a language and environment for statistical computing. R Foundation for Statistical Computing, Vienna

Reeve R (2006) Wildlife trade, sanctions and compliance: lessons from the CITES regime. Int Aff 82:881-897

Rivalan P, Delmas V, Angulo E, Bull LS, Hall RJ, Courchamp F (2007) Can bans stimulate wildlife trade? Nature 447: 529-530

Roberts CM, Bohnsack JA, Gell F, Hawkins JP, Goodridge R (2001) Effects of marine reserves on adjacent fisheries. Science 294:1920-1923

Roberts CM, McClean CJ, Veron JEN, Hawkins JP and others (2002) Marine biodiversity hotspots and conservation priorities for tropical reefs. Science 295:1280-1284

Sadovy Y (2005) Trouble on the reef: the imperative for managing vulnerable and valuable fisheries. Fish Fish 6: 167-185

Sadovy Y, Cheung W (2003) Near extinction of a highly fecund fish: the one that nearly got away. Fish Fish 4: 86-99

Editorial responsibility: Eric Gilman,

Honolulu, Hawaii, USA
Samoilys MA, Martin-Smith KM, Giles BG, Cabrera B, Anticamara JA, Brunio EO, Vincent ACJ (2007) Effectiveness of five small Philippines' coral reef reserves for fish populations depends on site-specific factors, particularly enforcement history. Biol Conserv 136:584-601

Shin YJ, Rochet MJ, Jennings S, Field JG, Gislason H (2005) Using size-based indicators to evaluate the ecosystem effects of fishing. J Mar Sci 62:384-396

Sutherland WJ, Pullin AS, Dolman PM, Knight TM (2004) The need for evidence-based conservation. Trends Ecol Evol 19:305-308

Tidd AN, Hutton T, Kell LT, Padda G (2011) Exit and entry of fishing vessels: an evaluation of factors affecting investment decisions in the North Sea English beam trawl fleet. J Mar Sci 68:961-971

Vincent ACJ, Meeuwig JJ, Pajaro MG, Perante NC (2007) Characterizing a small-scale, data-poor, artisanal fishery: seahorses in the central Philippines. Fish Res 86:207-215

Vincent ACJ, Foster SJ, Koldewey HJ (2011) Conservation and management of seahorses and other Syngnathidae. J Fish Biol 78:1681-1724

Western D, Wright W (1994) Natural connections: perspectives in community-based conservation. Island Press, Washington, DC

White AT, Alino PM, Meneses AT (2006) Creating and managing marine protected areas in the Philippines. Fisheries Improved for Sustainable Harvest Project, Coastal Conservation and Education Foundation and University of the Philippines Marine Science Institute, Cebu City

Wood SN (2006) Generalized additive models: an introduction with R. Chapman \& Hall, CRC Press, Boca Raton, FL

Yasué M, Nellas A, Vincent ACJ (2012) Seahorses helped drive creation of marine protected areas, so what did these protected areas do for the seahorses? Environ Conserv 39:183-193

Submitted: August 8, 2013; Accepted: August 20, 2014

Proofs received from author(s): January 15, 2015 